\title{
A Importância da Participação Cidadã nas Políticas de Saúde: 0 caso da reestruturação dos serviços de saúde materno-infantil em Portugal'
}

\section{Citizen Participation Relevance in Health Policies: the case of the maternal and child health services restructuring in Portugal}

\author{
Ana Raquel Matos \\ Investigadora do Centro de Estudos Sociais da Universidade de \\ Coimbra. Mestre em Sociologia e doutoranda do Programa "Go- \\ vernação, Conhecimento e Inovação" no Centro de Estudos Sociais/ \\ Faculdade de Economia da Universidade de Coimbra. \\ Endereço: Centro de Estudos Sociais, Colégio de São Jerónimo, \\ Largo D. Dinis, Apartado 3087, CEP 3001-401, Coimbra, Portugal. \\ Contacto: amatosळces.uc.pt \\ I Pesquisa financiada pela Fundação para a Ciência e a Tecno- \\ logia de Portugal (Ref SFRH/BD/40971/2007).
}

\section{Resumo}

As questões em torno da participação cidadã tornaram-se indiscutivelmente centrais na análise dos processos públicos de decisão das sociedades ditas democráticas. Uma das maiores dificuldades tem, no entanto, residido na ampla definição das modalidades participativas a considerar neste domínio. Neste trabalho assume-se que as ações de protesto são uma modalidade legítima de participar nos processos públicos de decisão. Analisa-se, para tal, o processo de encerramento de blocos de parto em Portugal, uma das medidas da recente reestruturação dos serviços de saúde materno-infantil, executada entre Maio de 2006 e Dezembro de 2007, e as consequentes ações de protesto encetadas pelas populações das localidades afetadas pela medida. Avalia-se a forma como a implementação não informada e participada de uma medida focada em critérios como segurança e qualidade da prestação de cuidados de saúde pode, mesmo assim, desencadear movimentos de contestação, sobretudo enquanto estratégia dos cidadãos para participar na (re)formulação de uma política pública.

Palavras-chave: Participação cidadã; Políticas de saúde materno-infantil; Acções de protesto; Encerramento de blocos de parto. 


\section{Abstract}

In the so-called democratic societies citizens' participation has become a central issue to the analysis of decision making processes. However, in this scope the major difficulty is related to a broad definition of what can be considered as participatory modalities. In this paper protest actions are assumed as legitimate forms of participation in public decision making processes. Accordingly, this work describes and analyses the maternity wards closure in Portugal, one of the measures of the recent restructuring of the maternal and child health services that was implemented between May 2006 and December 2007 , and the consequent protest actions developed by the local populations affected by the measure. It is also evaluated how a non-informed and communicated measure based on criteria such as security and quality of the provided health care can trigger protest movements, particularly as a strategy of citizens to participate in a public policy (re)formulation.

Keywords: Citizen Participation; Maternal and Child Health Policies; Protest Actions; Maternity Wards Closure.

\section{Democracia Deliberativa, Participação Cidadã e Ações de Protesto}

A história da humanidade transformou-se com o advento da democracia, a qual se tornou uma das suas maiores utopias, que nos tem obrigado a possibilitar a realização dos seus pressupostos mais básicos - a soberania popular e o governo pelo povo - e de alcançar uma democracia de mais alta intensidade (Font, 1998; Santos, 2002; Fung e Wright, 2003).

A presente abordagem enquadra as ações de protesto a partir da teoria da deliberação democrática e não encara o fenomeno como patologia social. Pelo contrário, considera os protestos enquanto possibilidades legítimas de participação cidadã em contextos públicos de decisão.

O caminho no sentido de sociedades mais democráticas passa pelo envolvimento ativo de todos os cidadãos que queiram integrar processos de tomada de decisão, numa tradução do que são processos de democracia participativa. Tal possibilidade não significa substituir modelos representativos por outros mais participativos. 0 reforço da democracia, pelo contrário, advém de uma combinação proveitosa entre ambos (Santos, 1998; Dryzek, 2009; Pearce, 2010).

A teoria da deliberação democrática é, assim, passagem obrigatória no entendimento de muitas destas questões, assentando no pressuposto de que a participação cidadã em processos de decisão, para além de contribuir para a qualidade das decisões, torna as sociedades mais democráticas (Dryzek, 2000, 2009; Gutmann e Thompson, 1996; Sanders, 1997; Bohman, 1998; Cohen, 1999).

Participar tem vindo a tornar-se uma expressão bastante trivial, usada por muitos, com muita frequência e em múltiplos contextos. A participação cidadã, no entanto, emerge num contexto de crise. Uma crise de legitimidade e de governabilidade, cuja solução só será alcançada se a esfera de decisão política se abrir à participação cidadã (Santos, 2005).

São vários os indicadores que dão conta da insatisfação em relação a uma democracia superficial, desinformada, alienada, baseada mais em personalidades do que em políticas públicas efetivas, o que faz aumentar o distanciamento dos cidadãos em relação 
à esfera política, a abstenção eleitoral e a descrença generalizada na forma como os políticos atuam e decidem (Mouffe, 200o; Stoker, 2006; Rosenberg, 2007; Pearce, 2010).

A participação cidadã é, portanto, uma das principais marcas da atualidade política e do debate que vem decorrendo no âmbito da ciência política. A prová-lo estão também as agendas políticas das sociedades ocidentais, onde a importância do envolvimento dos cidadãos em processos de decisão se tornou uma realidade incontornável.

Várias questões atravessam este debate, interessando sobremaneira a esta análise. 0 apelo para participar tem vindo a acontecer em múltiplos domínios da vida social, a diferentes ritmos e a partir de diferentes metodologias, dando conta da heterogeneidade, quer nos valores que justificam uma maior abertura à participação, quer nos objetivos que se preconizam. Também a institucionalização dessas práticas se afigura variável e pressupõe uma discussão mais precisa sobre quais são, afinal, os espaços legítimos de deliberação e participação, quem neles pode ser incluído e de que forma o pode fazer. Sobre isto, a já referida teoria da deliberação democrática tem vindo a elucidar, a partir, sobretudo, das suas mais recentes abordagens (Hendriks, 2006; Bächtinger e col., 2010; Elstub, 2010).

Os processos de deliberação assentes na participação cidadã são, então, encarados como estratégia para encorajar decisões com qualidade, mais justas porque se sustentam no conhecimento dos que vivem os problemas. Esta é, portanto, uma perspectiva alternativa de encarar o funcionamento de uma democracia que se quer mais democrática.

Considerar como pressuposto essencial da teoria da deliberação a possibilidade de inclusão nas decisões de grupos sociais usualmente excluídos contribui em larga medida para reforçar o enquadramento das ações de protesto como expressão nítida dessa reivindicação pela inclusão, sobretudo se entendermos deliberação como forma de governação das pessoas, com as pessoas e para as pessoas. No entanto, as ações de protesto nem sempre foram consideradas no âmbito da teoria da deliberação democrática. É recente a abertura à sua circunscrição na teoria e decorre de décadas de críticas cerradas a pressupostos demasiado normativos e desgarrados da realidade (Elstub, 2010). Na genese da deliberação democrática imperava o pressuposto do argumento racional de todo e qualquer cidadão livre e igual para intervir nos processos de decisão, orientados para o consenso, motivados pela ideia de bem comum e atentos às necessidades do outro (Cohen, 1999; Gutmann e Thompson, 1996; Dryzek, 2000; Held, 2007; Bächtiger e col., 2010).

As críticas elaboradas a tais pressupostos têm, no entanto, permitido alargar o escopo da deliberação democrática a outras formas de comunicação, para além da argumentação puramente racional, e considerando outros inputs nesses processos, como o humor, as emoções ou até as conversas mais banais do quotidiano (Sanders, 1997; Dryzek, 2009; Bächtiger e col., 2010).

Com isso, as novas abordagens deliberativas abrem-se ao espaço público, entendendo-o como espaço onde diferentes atores interferem nos assuntos públicos através da influência que exercem na opinião pública, num reconhecimento claro da importância que as interacções sociais que aí se circunscrevem detêm nos processos de decisão.

Mas a teoria começa também a ceder face à importância do antagonismo, do conflito e do confronto em sociedade, ideias que fundamentam uma governação baseada num pluralismo agonista defendido por Mouffe (2000, 2005), o que representa um enorme passo na consagração dos protestos como formas legítimas de participar nas decisões e, para além disso, no seu reconhecimento como órgão vital da democracia (Mouffe, 2005; Holston, 2007).

Assim, tais manifestações coletivas traduzem a intenção dos que não têm outra possibilidade de participar diretamente na estrutura decisional domesticada pelo Estado, de demonstrar terem voz, num ato de contra-poder ou de contra-democracia (Rosanvallon, 2006).

Os protestos são, assim, manifestações de poder contra-hegemonicas que tentam dar visibilidade à indiferença. São convulsões da sociedade civil que procuram a transformação social. São, ainda, a arte do empoderamento da esfera cidadã que se pretende ver reconhecida na e pela esfera do poder. Desta forma, a participação pode surgir motivada pela exclusão dos cidadãos, emergindo de forma insurgente e disruptiva (Holston, 2007), mas com 
potencial para conferir aos cidadãos o controle das decisões, à semelhança da realidade que se esconde no conceito política de contenção legado por Doug McAdam e colaboradores (2001). Por isso, importa tanto analisar, com detalhe, cada uma dessas manifestações em sociedade.

\section{A Decisão Controversa de Encerrar Blocos de Parto em Portugal}

Participar tornou-se palavra de ordem e qualquer decisão de interesse público pressupõe, cada vez mais, que se ouça a população afetada, numa tentativa de valorizar o seu conhecimento, ainda que leigo, sobre as principais questões que atravessam uma decisão.

Esta análise é orientada pelo pressuposto de que as ações de protesto se assumem como estratégia para influenciar os processos de decisão, corroborando uma definição mais ampla sobre o que significa participar. Parte da descrição e análise de uma política de saúde implementada pelo Governo português, em Março de 2006, e que gerou fortes movimentos de contestação popular.

A controvérsia iniciou-se com a decisão tomada pelo Ministro da Saúde, em funções no XVII Governo Constitucional (2005-2008), de encerrar as unidades de saúde que realizassem menos de 1500 partos por ano, o que ocasionou uma ampla discussão em torno de questões relacionadas com a saúde maternoinfantil, nomeadamente: os critérios usados para determinar a concentração do número de partos em determinadas unidades de saúde, a questão da segurança materno-infantil e a igualdade no acesso a serviços de qualidade.

Uma reestruturação similar havia sido realizada em 1989, quando se criou a primeira Comissão Nacional de Saúde Materna e Neonatal (CNSMN), responsável pela definição de uma série de ações que foram implementadas, ainda hoje em vigor, como a hierarquização de hospitais, a criação de hospitais de apoio perinatal, apoio perinatal diferenciado, as redes de referenciação materno-infantil, as unidades coordenadoras profissionais e medidas mais pontu- ais, mas nem por isso menos importantes, como a introdução do preenchimento obrigatório do boletim de saúde da grávida, que permite hoje a partilha rápida da informação mais relevante sobre a gestante e sua gestação entre diversos profissionais.

É da responsabilidade dessa primeira comissão a implementação da medida de concentração do número de partos em unidades de saúde com melhores condições e que, na altura, levou ao encerramento de cerca de 150 blocos de parto dos 200 que estavam em funcionamento.

É inegável que esta reestruturação permitiu uma extraordinária melhoria dos indicadores de saúde materno-infantil, hoje verificados no país, designadamente a taxa de mortalidade infantil, que tem vindo a decrescer vertiginosamente em Portugal, elevando-a dos últimos lugares do ranking mundial, com valores característicos dos países subdesenvolvidos, para os 10 países com melhores indicadores de saúde materno-infantil, com uma das mais baixas taxas de mortalidade infantil, rondando actualmente os 3,3\%.

À semelhança da reestruturação implementada em 1989, também a mais recente reestruturação partiu de uma comissão de avaliação dos serviços públicos de saúde materno-infantil, constituída por obstetras, pediatras e enfermeiros obstetras.

A 10 de Março de 2006, o resultado dessa avaliação foi entregue ao Ministro da Saúde sob a forma de relatório. Baseado numa das conclusões do relatório, mas apenas quatro dias após a sua recepção, a 14 de Março de 2006², o Ministro da Saúde assinou o Despacho Ministerial no 7495/2006 (2 ${ }^{a}$ série), determinando a concentração do número de partos em unidades de saúde que realizassem pelo menos 1500 partos/ano e consequentemente, salvo raras excepções, o encerramento das restantes unidades. O documento legal estabelece, assim, que "a prestação de cuidados eficiente em locais que reúnam os meios técnicos e humanos apenas é garantida em maternidades com 1500 partos/ano" (Portugal. 2006, p. 5038), rácio que permitiria aos profissionais de saúde realizar um número suficiente de partos de forma a confrontarem-se com situações raras e

2 O curto intervalo de tempo entre a data de entrega do relatório e a data de publicação do Despacho Ministerial foi alvo de forte contestação, por transparecer a ideia de que o relatório apenas serviu para legitimar uma decisão que já estava tomada. 
a estarem preparados para as resolver. Para além disso, nessas unidades de saúde estaria garantida a presença permanente de, pelo menos, dois obstetras, um anestesista e um pediatra neotatologista (entre outros recursos mencionados, técnicos e humanos).

Partindo do critério de eficiência baseado no rácio estabelecido, da rede de 50 maternidades do Serviço Nacional de Saúde português: 27 reuniam condições técnicas para manter os blocos de parto em funcionamento e 23 não reuniam. Dentre as últimas: em 15 ocorriam menos de 1200 partos/ano; em 12 menos de 1000 partos/ano; e em 5 menos de 500 partos/ano.

O despacho intentou no encerramento concreto de 13 blocos em distintas localidades do país. ${ }^{3}$ Não obstante, por questões de difícil acessibilidade a serviços próximos e potencial sobrelotação de algumas unidades, encerrou 9 blocos de parto. A população dessas localidades protestou, de diversas maneiras, durante cerca de dois anos contra o encerramento destes serviços.

\section{Metodologia}

Os dados que sustentam a presente análise são de base qualitativa, obtidos mediante recurso a diferentes técnicas de recolha de dados:

a) Realização de entrevistas semi-estruturadas a um leque de atores centrais, num total de 28 entrevistas (4 líderes de movimentos cívicos que mobilizaram os protestos locais contra o encerramento de blocos de parto, 3 comandantes de corporações de bombeiros que prestam serviço de transporte a doentes urgentes, 4 diretores de maternidades onde se encerraram blocos de partos e de outras para onde foram reencaminhadas as parturientes, 2 membros da CNSMN; 1 elemento do Observatório Nacional das Políticas de Saúde e 13 cidadãos residentes nas zonas afetadas pela decisão). Na impossibilidade de analisar detalhadamente os 9 contextos territo- riais onde se efetivaram encerramentos, optou-se por analisar com maior detalhe 4 das 9 localidades afetadas pela medida, designadamente Figueira da Foz, Elvas, Mirandela e Barcelos, aquelas onde mais se protestou, de acordo com informação resultante da análise de imprensa (ver alínea c). Para além disso, a opção pelos atores entrevistados prendeu-se com os seguintes critérios: líderes dos movimentos cívicos criados em defesa das maternidades locais por se assumirem como os interlocutores dos que protestaram; comandantes das corporações dos bombeiros, para conhecer os contornos da problemática do transporte das parturientes; diretores das maternidades, para aferir sua sensibilidade aos critérios avançados para os encerramentos e conhecer as consequências da concentração nas maternidades onde os partos passaram a ser concentrados; membros da CNSMN, com o intuito de perceber como foi acolhida a medida do Governo, que descurou grande parte das sugestões do relatório, sobretudo a relativa à importância de se ouvir a população; cidadãos das localidades estudadas, para aferir, de forma exploratória, a sua sensibilidade aos protestos e à medida implementada.

b) Análise documental (legislação sobre a temática, relatório da CNSMN, protocolos estabelecidos no âmbito da prestação de cuidados de saúde pré-natal e durante o parto, documentação do Ministério da Saúde sobre cuidados maternos e neonatais e relatórios de estudos complementares envolvendo questões de saúde materna e neonatal).

c) Análise de imprensa, num total de 497 notícias coletadas (designadamente dos jornais nacionais online: Jornal de Notícias, Expresso e Diário de Notícias).

\section{De que se alimentou a controversa reestrutura- ção dos serviços de saúde materno-infantil em Portugal?}

Foram vários os argumentos implicados na reestruturação dos serviços de saúde materno-infantil

\footnotetext{
3 Barcelos, Santo Tirso, Lamego, Oliveira de Azeméis, Torres Vedras, Elvas, Amarante, Figueira da Foz, Cascais, Chaves e Vila Franca de Xira. Para além dessas, o despacho refere que, no Nordeste Transmontano, a respectiva Administração Hospitalar deveria informar o Ministério da sua decisão sobre a concentração deste tipo de serviço, das duas unidades existentes (Mirandela e Bragança) numa, a qual informou manter a unidade de Bragança. Numa lógica semelhante, solicitou-se aos três hospitais da Beira Interior que, entre administrações e profissionais, decidissem sobre a concentração numa única unidade, não tendo até à data sido tomada qualquer decisão.
} 
em Portugal. Uma das questões que mais gerou desacordo opôs os argumentos avançados no relatório da CNSMN e o Despacho Ministerial aos argumentos apresentados pela população $0^{4}$, que protestou contra os encerramentos. 0 relatório de avaliação propôs a concentração do número de partos (determinada a partir do rácio 1500 partos/ ano) em unidades capazes de garantir serviços de qualidade e que dispusessem de um contingente humano (com formação especializada) e técnico em número suficiente. Avançou com o argumento de que a política de concentração contribuiria para a promoção de serviços de qualidade e que esbateria eventuais desigualdades no acesso da população a serviços de saúde eficientes.

o Despacho Ministerial que veio regular esta matéria, consagrou a adoção da medida de concentração do número de partos a realizar em unidades com mais de 1500 partos/ano, sugerida pelo relatório, ignorando, a aplicação de medidas relacionadas com a dimensão técnica e/ou relativa aos recursos humanos. As populações dos locais afetados, considerando a medida de concentração como uma estratégia economicista (uma medida de poupança e não de investimento nestes serviços), sentindo-se lesadas com a decisão, desencadearam várias ações de protesto.

\section{Quadro I - Síntese dos argumentos apresentados em torno da política de concentração de partos}

\begin{tabular}{|c|c|c|c|}
\hline & Relatório da CNSMN & $\begin{array}{l}\text { Despacho Ministerial } \\
\text { n 7495/2006 }\end{array}$ & Os protestos populares \\
\hline $\begin{array}{l}\text { Recursos humanos/ } \\
\text { técnicos }\end{array}$ & $\begin{array}{l}\text { Sugere a reorganização } \\
\text { (investimento) dos recursos } \\
\text { humanos e técnicos: manutenção } \\
\text { dos serviços onde se executem } \\
\text { pelo menos } 1500 \text { partos/ano. } 0 \\
\text { cumprimento deste indicador } \\
\text { reverte a favor de da qualidade } \\
\text { dos serviços a prestar e de } \\
\text { igualdade no seu acesso. }\end{array}$ & $\begin{array}{l}\text { Número de partos realizados } \\
\text { como factor determinante } \\
\text { para o encerramento ( } 1500 \\
\text { partos/ano). Ao encerrar as } \\
\text { unidades que se situem abaixo } \\
\text { do valor indicado aposta } \\
\text { na qualidade dos serviços a } \\
\text { prestar e favorece a igualdade } \\
\text { no acesso a esses serviços. }\end{array}$ & $\begin{array}{l}\text { Insurgem-se contra a estratégia } \\
\text { economicista do Governo, que } \\
\text { não se traduz em qualidade dos } \\
\text { serviços a prestar. Reclamam } \\
\text { serviços de proximidade; } \\
\text { identidade regional colocada em } \\
\text { causa com a adopção da medida } \\
\text { e combatem uma medida que } \\
\text { agrava as desigualdades regionais }\end{array}$ \\
\hline $\begin{array}{l}\text { Serviço de transporte } \\
\text { de doentes urgentes }\end{array}$ & $\begin{array}{l}\text { Sugere uma reestruturação deste } \\
\text { serviço. Indica que a maternidade } \\
\text { mais próxima não deve distar } \\
\text { mais de } 20 \mathrm{Km} \text { ou 30' e que o } \\
\text { transporte deve ser efetuado na } \\
\text { presença de técnico especializado } \\
\text { (enfermeiro/a com especialidade } \\
\text { em saúde materno-infantil). }\end{array}$ & $\begin{array}{l}\text { Menciona que vai projetar } \\
\text { melhorias, mas sem lhes fazer } \\
\text { qualquer referência. }\end{array}$ & $\begin{array}{l}\text { Argumentam sobre o aumento } \\
\text { de nascituros que nascem em } \\
\text { contexto não hospitalar, sobretudo } \\
\text { a caminho da maternidade mais } \\
\text { próxima. } \\
\text { Referem a falta de formação dos } \\
\text { profissionais que acompanham a } \\
\text { parturiente ao nível dos cuidados } \\
\text { de saúde neonatal. }\end{array}$ \\
\hline $\begin{array}{l}\text { Participação cidadã na } \\
\text { decisão }\end{array}$ & $\begin{array}{l}\text { Alerta que a reestruturação dos } \\
\text { serviços não dispensa consulta } \\
\text { prévia à população (autarcas e } \\
\text { administradores locais de saúde). }\end{array}$ & $\begin{array}{l}\text { Ignorou a participação cidadã } \\
\text { na decisão. }\end{array}$ & $\begin{array}{l}\text { Consideram os encerramentos } \\
\text { um ato de prepotência política e } \\
\text { reclamam o direito de participar } \\
\text { na decisão. }\end{array}$ \\
\hline $\begin{array}{l}\text { Os serviços privados de } \\
\text { saúde materno-infantil }\end{array}$ & $\begin{array}{l}\text { Sugere uma avaliação e } \\
\text { reestruturação nos mesmos } \\
\text { moldes. }\end{array}$ & $\begin{array}{l}\text { Projeta a sua avaliação num } \\
\text { futuro próximo. }\end{array}$ & $\begin{array}{l}\text { Temem o crescimento da rede de } \\
\text { serviços privados e desigualdades } \\
\text { no acesso a estes serviços. }\end{array}$ \\
\hline
\end{tabular}

4 A informação que sustenta os argumentos apresentados pela população, aqui considerada, foi colectada em entrevistas realizadas aos líderes dos movimentos cívicos criados em defesa das maternidades encerradas estudadas e através da análise de imprensa efectuada. Também as entrevistas exploratórias realizadas a moradores das localidades estudadas contribuíram com argumentos válidos para esta análise. 
Os protestos populares argumentaram, sobretudo, contra a estratégia de poupança de recursos levada a cabo pelo Governo. Não considerando que a concentração do número de partos se traduzisse em melhores serviços a prestar e na igualdade no seu acesso, a população reclamou pela manutenção de serviços de proximidade. Para além disso, contrapuseram ao argumento da qualidade e da igualdade o argumento da identidade. Ou seja, ao impossibilitar o nascimento na região de residência, a população sentiu-se lesada na sua dimensão identitária. Este argumento, contudo, constituiu uma reivindicação de foro "mais emocional" já que medidas foram tomadas de forma a garantir que o local de nascimento seja aferido pela residência de um dos progenitores do recém-nascido e não pelo local onde se realiza o parto. 5

Outro argumento avançado prende-se com a questão do transporte da parturiente, considerado pela Comissão como alvo prioritário de reestruturação já que "os serviços não estão organizados" (Portugal. CNSMN, 2006, p. 8), adiantando que para distâncias iguais ou superiores a $20 \mathrm{Km}$ ou a 30 minutos, esse deveria passar a ser efetuado na companhia de um(a) enfermeiro(a) especialista. 0 despacho ministerial refere à necessidade de se proceder a essa reestruturação, mas sem indicar como e quando pretende executá-la. Perante esta lacuna, e face ao crescente número de partos ocorridos em contexto extra hospitalar e dada a ausência de acompanhamento das parturientes por profissionais de saúde especializados, a população encontrou aqui um forte argumento contra a medida.

De extrema importância para esta análise é o argumento sobre a necessidade de envolver a população na tomada de decisões, que foi totalmente negligenciado pelos decisores políticos, apesar das advertências patentes no relatório da CNSMN nesse sentido (embora a sugestão fosse adstrita à consulta de autarcas e administradores locais de saúde). Este veio a tornar-se também num dos argumentos mais proclamados, já que a população manifestou amplamente o seu descontentamento por não ter sido consultada, informada e ouvida durante o processo de decisão, situação que consideraram "prepotência política".

Durante a controvérsia argumentou-se ainda sobre a pertinência de avançar, nos mesmos moldes, com a uma avaliação dos serviços privados, ${ }^{6}$ sobretudo por "não haver mecanismos de controle de qualidade dos serviços prestados fora da Rede de Referenciação Materno-Infantil" (Portugal. CNSMN, 2006, p. 6), ao que o despacho responde "encontrarse em curso tal regulamentação". Também a população acentuou a importância dos serviços privados na controvérsia, considerando jogarem um papel determinante no quadro das assimetrias no acesso a serviços de proximidade.

Atentando na figura 1, percebe-se, desde logo, a existência de uma distribuição assimétrica dos serviços ao longo do território, tornando-se clara a concentração, quer de serviços públicos, quer privados, na região Centro e Norte Litoral. Não obstante estes serviços também se concentram em zonas de maior densidade populacional, tal não deixa de constituir um problema no acesso desigual aos serviços ao longo do território.

Sobre esta matéria, no entanto, e considerando as referidas medidas tomadas na reestruturação dos serviços de saúde materno-infantil, o Ministério da Saúde revelou discricionariedade no tratamento do serviço públicos e do privado.

A Entidade Reguladora da Saúde ${ }^{7}$, no seu mais recente relatório de caracterização dos prestadores não públicos de cuidados de saúde com centros de nascimento (Portugal. ERS, 2007), tece conclusões

\footnotetext{
5 A medida em análise, ao determinar o encerramento do bloco de partos do Hospital de Elvas e a possibilidade de os seus habitantes poderem nascer na maternidade de Badajoz, Espanha, levou a que se legislasse sobre esta matéria: Lei n 29/2007, de 2 de Agosto (que determina que o registo de crianças portuguesas dos concelhos de Elvas e Rio Maior que nasçam em Badajoz tenham como naturalidade o local de residência de um dos pais).

6 Recomendação, aliás, já firmada em relatório intercalar, datado de 2004 e entregue ao Ministério da Saúde.

7 A Entidade Reguladora da Saúde é uma entidade de regulação e supervisão do sector da prestação de cuidados de saúde, independente no exercício das suas funções, cujas atribuições se desenvolvem em áreas fundamentais relativas ao acesso aos cuidados de saúde, à observância dos níveis de qualidade e à garantia de segurança, zelando pelo respeito das regras da concorrência entre todos os operadores, no quadro da prossecução da defesa dos direitos dos usuários.
} 
Figura I - Distribuição pelo território das unidades de saúde que realizam partos

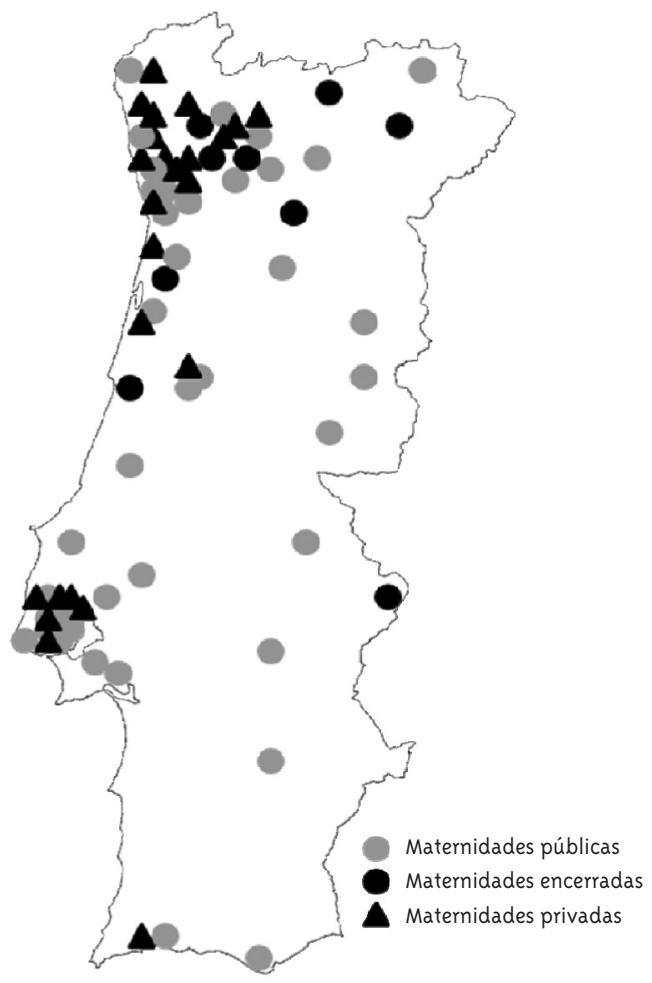

descoincidentes com as defendidas para o serviço público: para este, o critério central segurança/qualidade para encerrar blocos de parto recaiu no rácio 1500 partos/ano; para o serviço privado, para além de não se aplicar o mesmo critério, não se considerou o mesmo indicador. Ou seja, ao invés do encerramento, a sugestão avançada passou simplesmente pelo "investimento na melhoria das condições" (Portugal. ERS, 2007, p. 9). Quanto ao número de partos, comparativamente com a análise feita para o serviço público, apenas duas das 25 unidades do serviço privado realizavam mais de 1500 partos/ano. ${ }^{8}$ Nas restantes a média é de 5 partos por semana (cerca de 270 partos/ano), um valor em muito inferior ao registado no público e que nem por isso determinou qualquer encerramento.

Para além do número de partos realizados nos serviços privados se apresentar com valores muito inferiores aos do público, a sua avaliação reportou outras fragilidades incomparavelmente superiores às registadas nos serviços públicos, nomeadamente, o incumprimento dos indicadores mínimos de segurança (técnicos, recursos humanos e infraestruturas):

"Nós chamamos para a discrepância brutal que havia entre o tratamento que o Estado estava a dar aos serviços públicos em relação aos serviços privados [...] e se o argumento é a saúde pública não se pode admitir que haja um tratamento diferente, mas a verdade é que houve!" (Membro do Observatório Português dos Sistemas de Saúde)

\section{Os Protestos como Participação}

A análise de imprensa efetuada, para além de permitir determinar os distintos atores envolvidos na controvérsia, permitiu também verificar que as ações de protesto se iniciaram antes mesmo da sua oficialização pelo despacho ministerial, tendo perdurando durante os anos de 2006 e 2007, ou seja, ao longo do seu período de implementação determinado no despacho. Embora atualmente já não se registem manifestações de rua, os protestos continuam a fazer-se sentir, embora em menor escala, sobretudo nos discursos dos intervenientes locais sempre que a controvérsia emerge no espaço público.

Na tomada de conhecimento da medida, foram várias as ações de protesto desencadeadas um pouco por todo o país, sobretudo durante esses dois anos, desde concentrações populares, abaixo-assinados, cortes de estradas, marchas lentas, vigílias, imposição de símbolos de luto nos edifícios e espaços públicos e o recurso a ações judiciais (como a interposição de providências cautelares).

Considerando que a decisão afetou umas localidades mais do que outras, também os protestos acabaram por se localizar, a que não será estranho o fato de ser nos espaços locais que as pessoas integram redes sociais capazes de potenciar o sucesso deste tipo de ações reivindicativas, assim como a sua sustentabilidade no tempo (Estanque, 1999; Mendes e Seixas, 2005).

8 Hospital da Cruz Vermelha e CUF, ambos em Lisboa. 
Figuras 2, 3 e 4 - A contestação popular ao encerramento dos blocos de parto
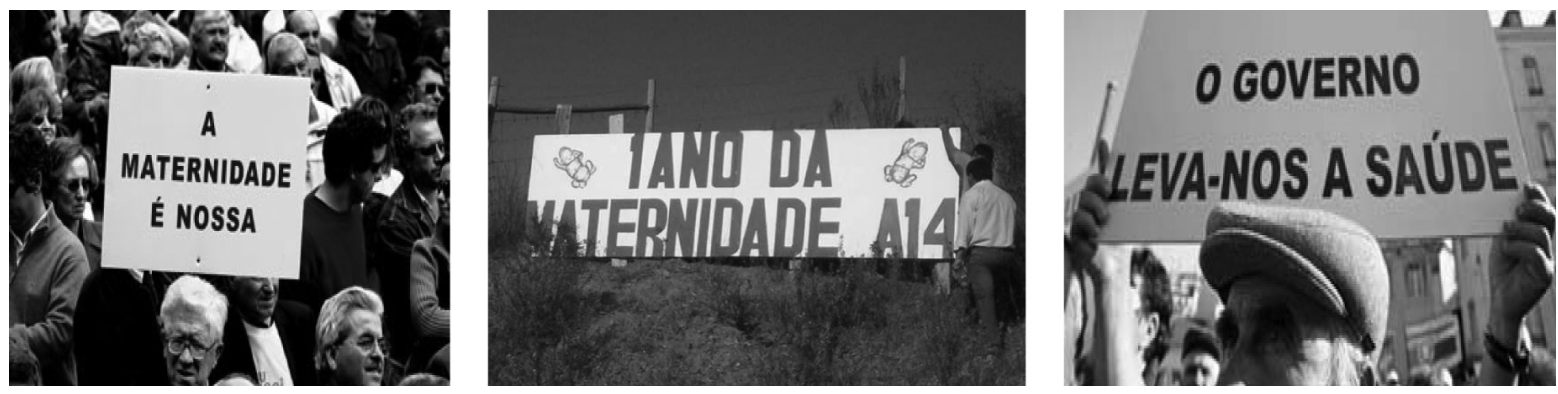

Fonte: Imagens veiculadas pela imprensa nacional.

É a partir da contestabilidade das decisões que se legitima a participação dos cidadãos considerados coletivos afetados (Callon e col., 2001), numa clara atitude de denúncia e de crítica com vista à transformação. Da mesma forma se entendem também os protestos, neste caso em defesa de serviços de saúde, como parte integrante da democracia.

Neste caso, os protestos invocaram, essencialmente, a falta de planejamento da medida e contestaram uma decisão governamental autocentrada, não permeável a qualquer tentativa de diálogo e de participação na decisão, não estando aqui em causa a discussão dos critérios invocados e aplicados na reestruturação dos serviços, até porque na esmagadora maioria dos casos eles não chegaram a ser do conhecimento da população.

\section{Os Principais Atores Envolvidos nos Protestos}

\section{A população}

Os habitantes das localidades onde encerraram maternidades surgem como intervenientes centrais da controvérsia. Não obstante, grande parte da mobilização cidadã foi impulsionada pelos partidos de oposição ao Governo que se encontravam na gestão das autarquias locais onde encerraram blocos de parto. Nas localidades que mais protestaram, os autarcas assumiram quase sempre a função de porta-vozes da população, organizando e liderando as ações de protesto que foram sendo desencadeadas. Noutros casos, as presenças político-partidárias fizeram-se notar de várias formas como, por exemplo, através

Figuras 5 e 6 - A contestação política ao encerramento de blocos de parto
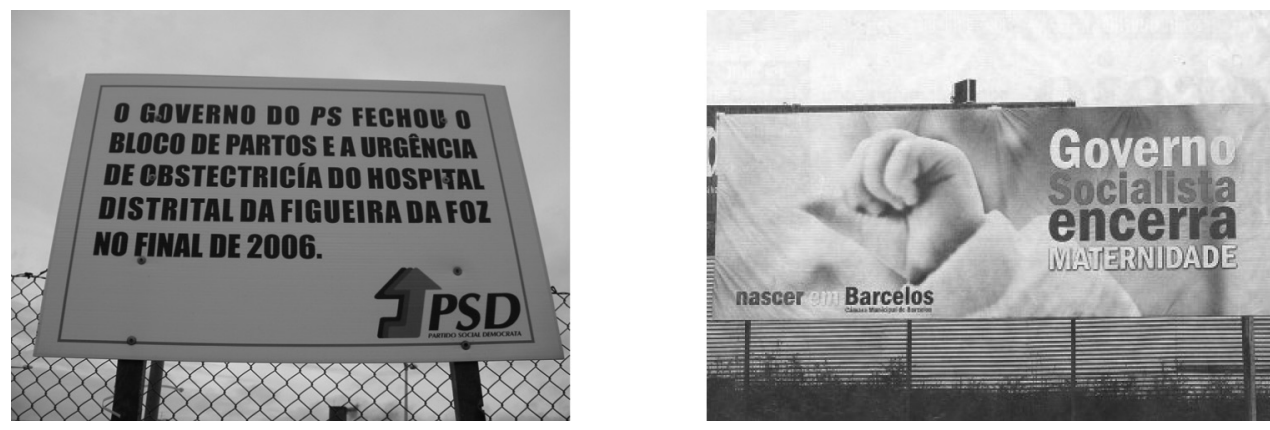

Fonte: Fotografias da autora. 
de outdoors com palavras de ordem, colocados em pontos estratégicos do país e com carimbo políticopartidário. Nas localidades afetadas onde se criaram movimentos cívicos em defesa da reabertura dos serviços, esses eram, quase sempre, liderados por indivíduos com vínculos políticos que eram do conhecimento público.

A tomada de posição contrária à decisão política de encerrar blocos de parto assentou numa ordem variada de razões. A mais reclamada prende-se com a manutenção de serviços de proximidade:
"Todo o português quer ter um centro de saúde ao lado de casa, uma farmácia em frente, o talho a lado, quer ter uma quinta pequenina onde vai cultivar meia dúzia de pés de batata e meia dúzia de couves [...]." (Membro da CNSMN, 3 de Setembro de 2006 em www.solidariedade.pt).

Reivindicou-se identidade regional que, segundo a população, seria afetada pela decisão, apesar da clara regulamentação desta matéria garantir a “pertença”, por nascimento, à morada de residência de um dos progenitores dos recém-nascidos.

Figuras 7, 8 e 9 - A contestação identitária ao encerramento de maternidades
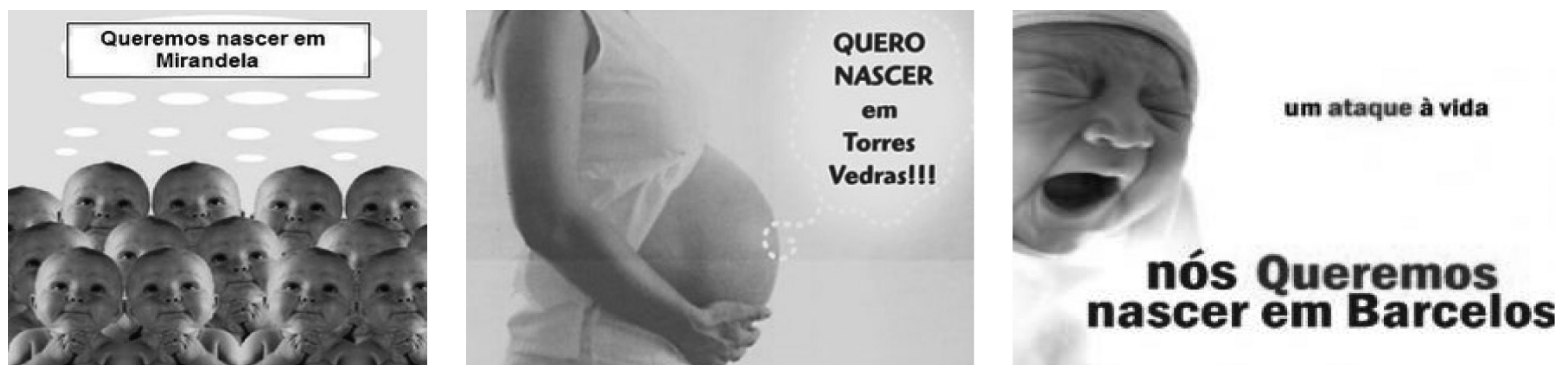

Fonte: Outdoors utilizados em diferentes localidades onde ocorreram protestos.

Porém, uma das mais fortes reivindicações prendeu-se com a exigência do cumprimento do direito, por parte do cidadão, de participar nos processos de decisão política, o qual aparece consagrado, enquanto princípio fundamental, na Constituição da República Portuguesa (art. $2^{\circ}$, art. $9^{\circ}$ e art. $4^{\circ}$ ):

"O cidadão tem entre os direitos inscritos no seu caderno, o direito à indignação e ao protesto. 0 que aconteceu com o encerramento das maternidades [...] é algo que está muito inscrito na matriz deste governo. Um posicionamento alheado da realidade, de tudo querer das populações. Uma atitude altamente desrespeitosa da vontade do outro, da razão do outro, que se nota na negociação seja do que for". (Líder de movimento cívico pela defesa de uma maternidade local)

Relativamente à questão da segurança e qualidade, que norteou a ação de reestruturação que levou ao polemico encerramento de blocos de par- to, a população considerou estar em causa uma medida de falta de investimento em serviços de saúde materno-infantil que o Governo disfarçou sob argumentos de segurança e qualidade da mulher e recém-nascidos.

Não se pode ainda ignorar que as desigualdades regionais no acesso a serviços de qualidade, que segundo as medidas governamentais viriam a ser esbatidas, foram entendidas pela população como uma estratégia para impulsionar o crescimento de serviços de saúde privados.

\section{Os responsáveis pelos serviços de transporte ur- gente das parturientes}

De forma mais discreta, mas presentes nas ações de protesto, estiveram algumas corporações de bombeiros. Através de protocolo estabelecido com o Instituto Nacional de Emergência Médica (INEM), essas corporações são responsáveis pelo transporte de doentes urgentes. Sobre a medida, argumenta- 
ram contra a sua falta de planejamento e contra o facto de também eles não terem participado na sua definição nem sequer terem sido informados sobre a sua execução.

Mas a questão que mais implica estes actores nas acções e protesto prende-se com o número de crianças nascidas em contexto extra-hospitalar, sobretudo em ambulâncias, a caminho da maternidade mais próxima, e as novas exigências em termos de desempenho profissional.

\section{Tabela I - Total de nascimentos segundo o local do parto}

\begin{tabular}{lccc} 
& 2003 & 2005 & 2008 \\
Domicílio & 671 & 568 & 844 \\
Hospital/clínica & 104453 & 101746 & 96064 \\
Outro & 177 & 109 & 1050 \\
\hline TOTAL & 105301 & 102423 & 97958 \\
\hline
\end{tabular}

Fonte: Instituto Nacional de Estatística, Estatísticas da Saúde.

Pela tabela anterior se percebem as tendências desenhadas e que podem estar relacionadas com os encerramentos executados a partir de 2006. Embora a taxa de natalidade tenha vindo a diminuir a nível nacional, diminuiu também o número de partos realizados em contexto hospitalar, devendo atentar-se, assim, no aumento do número de partos feitos no domicílio, mas essencialmente nos partos ocorridos em outro local, compreendendo todo o leque de situações não enquadráveis nas duas outras opções (domicílio, hospital/clínica) e onde se enquadram, por exemplo, os partos ocorridos em ambulâncias e outros meios de transporte.

\section{Os profissionais de saúde}

Manifestaram-se ainda contra a medida alguns elementos da classe médica, sobretudo médicos da especialidade em ginecologia-obstetrícia que exerciam funções nas unidades encerradas (apesar da posição oficial favorável ao encerramento emitida pelo Colégio da Especialidade na Ordem dos Médicos). Esses profissionais não consideravam a hipótese de continuarem num serviço onde não pudessem realizar partos na sua prática quotidiana.
Também alguns médicos da especialidade em medicina geral e familiar, embora sem emitirem uma posição oficial, manifestaram desacordo com a política de encerramento, sobretudo por temerem o aumento do número de gravidezes a acompanhar nos Centros de Saúde onde exerciam funções, uma das orientações patentes no relatório redigido pela comissão de peritos, alegando falta de formação específica para esse acompanhamento. Para além disso, considerando o cenário nacional de carência, sobretudo em determinadas zonas do país, de médicos dessa especialidade e as listas de espera de meses para obtenção de consultas de rotina, o previsível aumento de situações clínicas a acompanhar por esses profissionais apenas viria agravar a situação. Na sua opinião, a medida veio contrariar o argumento da qualidade dos serviços a prestar e da segurança, pelo menos em relação à vigilância pré-natal.

Também a Ordem dos Enfermeiros, apesar de anuir com a medida política, reivindicou maior investimento na formação de enfermeiros com especialidade em obstetrícia e em saúde infantil e perinatal, como afirmou no parecer emitido sobre "condições para o funcionamento de maternidades", onde deixou claro o cenário de escassez e consequente necessidade de se dotarem as equipas de assistência ao parto com estes profissionais.

Em relação ao transporte adequado de parturientes, o posicionamento da Ordem dos Enfermeiros mostrou-se avesso às condições em que continua a assegurar-se o transporte das parturientes, por considerar que este sempre se fez, e continua a fazer, em condições de risco.

\section{Comentários Finais}

Passados cinco anos desde que se executou uma das medidas mais pertinentes do plano de reestruturação dos serviços de saúde materno-infantil, o assunto continua a marcar presença no debate político nacional. A posterior avaliação desses serviços privados de saúde veio reacender a discussão em torno da questão, levando o hemiciclo político a renovar pedidos de explicação sobre a decisão e, sobretudo, sobre os critérios para o tratamento desigual dado pelo Governo aos serviços de saúde públicos e aos privados. 
Não se questionaram, neste trabalho, os critérios técnicos de segurança e qualidade propostos pelo relatório da comissão de peritos e o possível incremento que pode ter provocado na qualidade dos cuidados saúde materno-infantil, nem tampouco as melhores intenções por parte de quem implementou e executou a medida. 0 que esta pesquisa tenta evidenciar é a pertinência que assume o diálogo, a articulação e a interacção que deve existir entre Estado e sociedade civil, organizada e não organizada, na definição de políticas, neste caso políticas de saúde, e que não existiu em momento algum neste processo de decisão: nem durante a concepção da medida, nem durante o período mais intenso de contestação.

Nas boas práticas de concepção política em contextos democráticos são centrais conceitos como participação, visão estratégica, planejamento, prestação de contas e co-responsabilização, de forma a evitar ações de protesto como estratégia para participar nas decisões. Do modo como este processo decorreu, o que se apresentou com solução para um problema de falta de segurança e de qualidade, depressa se transformou, no entendimento cidadão, numa medida de retração do serviço público e da protecção social da saúde, coadjuvada com uma imagem de pouca sensibilidade social por parte do Estado português.

Neste quadro de análise, as ações de protesto desencadeadas não foram encaradas pelo poder político como espaços legítimos de participação cidadã, apenas como momentos de desacato à ordem pública, não tendo exercido qualquer impacto na medida implementada. Não obstante, serviram, de forma indirecta, para antecipar a ação do Governo e criar espaços de diálogo paralelos. Em certas localidades (Amarante, Lamego e Oliveira de Azeméis) os protestos sobre a medida levaram à visita imediata do Ministro da Saúde que, apesar de não dialogar sobre o encerramento destes serviços, acabou por se comprometer com a população a construir novas valências de saúde ou a requalificar as existentes. Desta forma, os protestos podem não ter exercido um impacto direto na medida implementada, mas ocasionaram consequências indiretas na melhoria de alguns serviços de saúde locais.

Protestos como os que aqui se retrataram visam a mudança política, nem sempre permitida pelos representantes dos cidadãos no poder, que ignoram o princípio da soberania popular. Detém, no entanto, a capacidade de "ferir de morte" um Governo. Neste caso, estes e outros protestos motivados por reestruturações do sistema nacional de saúde, por muito bem-intencionados que tivessem sido, levaram à queda do Ministro que executou tais medidas de forma autista.

Esta análise vem demonstrar que uma aposta maior, por parte do Estado, no cuidado a ter com a implementação informada de medidas de saúde, contemplando a opinião e a visão de todos os envolvidos, sobretudo dos cidadãos, e com as especificidades da região, poderia ter tido resultados mais benéficos: não só para os políticos envolvidos na contestação que irremediavelmente, optando pelo silêncio e decisão autocentrada, acabaram por sair prematuramente do poder, como para a população, para não ter de demonstrar pelo protesto o seu direito de interferir nas decisões tomadas pelo Estado.

\section{Referências}

BÄCHTINGER, A. et al. Symposium: toward more realistic models of deliberative democracy disentangling diversity in deliberative democracy: competing theories, their blind spots and complementarities. The Journal of Political Philosophy, Chicago, v. 18, n. 1, p. 32-63, 2010. BOHMAN, J. Survey article: The coming age of deliberative democracy. The Journal of Political Philosophy, Chicago, v. 6, n. 4, p. 40o-425, 1998. CALLON, M.; LASCOUMES, P. ; BARTHE, Y. Agir dans un monde incertain: essai sur la démocratie technique. Paris: Seuil, 2001.

COHEN, J. Changing paradigms of citizenship and the exclusiveness of the demos. International Sociology, Toronto, n. 14, p. 245-268, 1999.

DRYZEK, J. Deliberative democracy and beyond. Oxford: Oxford University Press, 2000.

DRYZEK, J. Democratization as deliberative capacity building. Comparative Political Studies, Thousand Oaks, California, v. 42, n. 11, p. 13791409, Apr. 2009. 
ELSTUB, S. The Third generation of deliberative democracy. Political Studies Review, Sheffield, n. 8, p. 291-307, Sep. 2010.

ESTANQUE, E. Acção colectiva, comunidade e movimentos sociais: para um estudo dos movimentos de protesto público. Revista Crítica de Ciências Sociais, Coimbra, n. 55, p. 85-111, nov. 1999.

FONT, N. New instruments of citizen participation. Working Papers, Barcelona, n. 152, p. 1-19, 1998.

FUNG, A.; WRIGHT, E. O. (Eds.) Deepening emocracy: institutional innovations in empowered participatory governance. London: Verso, 2003.

GUTMANN, A.; THOMPSON, D. Democracy and disagreement. Cambridge, MA: Harvard University Press, 1996.

HELD, D. Models of democracy. Cambridge: Polity Press, 2007.

HENDRIKS, C. Integrated Deliberation: Reconciling Civil Society's Dual Role in Deliberative Democracy. Political Studies Review, Sheffield, v. 54, p. 486-508, 2006.

HOLSTON, J. Insurgent citizenship: disjunctions of democracy and modernity in Brazil. Princeton: Princeton University Press, 2007.

MCADAM, D.; TARROW; S.; TILLY, C. Dynamics of contention. Cambridge: Cambridge University Press, 2001.

MENDES, J. M.; SEIXAS, A. M. Acção colectiva e protesto em Portugal (1992-2002). Revista Crítica de Ciências Sociais, Coimbra, n. 72, p. 99-127, out. 2005 .

MOUFFE, C. The Democratic paradox. London: Verso, 2005.

MOUFFE, C. Deliberative democracy or agonistic pluralism. Reihe Politikwissenschaft/ Political Science Series 72, Viena, p. 1-30, 2000. Disponível em: <http://www.ihs.ac.at/publications/pol/pw_72. pdf $>$. Acesso em: 26 mar. 2010.

PEARCE, J. Introduction. In: PEARCE, J. (Ed.) Participation and democracy in the Twenty-First Century city. New York: Palgrave Mcmillan, 2010. p. 1-33.
PORTUGAL. Despacho n. 7.495/2006 Diário da República - II Série, n. 67, p. 5037-5039, abr. 2006.

PORTUGAL. Comissão Nacional de Saúde Materna e Neonatal (CNSMN) Organização Perinatal Nacional. Programa de Saúde Materna e Neonatal. Lisboa: [s.n.], 2006.

PORTUGAL. Constituição da República Portuguesa. VII Revisão Constitucional, 2005. Disponível em: <http://www.

parlamento.pt/Legislacao/Paginas/

ConstituicaoRepublicaPortuguesa.aspx >. Acesso em: 27 mar. 2010.

PORTUGAL. Entidade Reguladora de Saúde (ERS) Caracterização dos prestadores de cuidados de saúde com centros de nascimento. Lisboa: Entidade Reguladora da Saúde, 2007.

PORTUGAL. Lei n. 29/2007. Diário da República - I Série, n. 148, p. 4921-4922, ago. 2007.

ROSANVALLON, P. La contre-démocratie. Paris: Éditions du Seuil, 2006.

ROSENBERG, S. An introduction: theoretical perspectives and empirical research on deliberative democracy. In: ROSENBERG, S. (Ed.) Deliberation, participation and democracy. Can the people govern? New York: Palgrave Macmillan, 2007. p. 3-22.

SANDERS, L. Against Deliberation. Political Theory, Thousand Oaks, California, v. 25, n. 3 p. 345-376, june 1997.

SANTOS, B. de S. Reinventar a democracia. Lisboa: Gradiva, 1998.

SANTOS, B. S. (Ed.) Democratizar a democracia: os caminhos da democracia participativa. Rio de Janeiro: Civilização Brasileira, 2002.

SANTOS, B. S. Crítica da governação neoliberal:

o Fórum Social Mundial como legalidade cosmopolita subalterna. Revista Crítica de Ciências Sociais, Coimbra, n. 72, p. 7-44, out. 2005.

STOKER, G. Why politics matters: making democracy work. Basingstoke: Palgrave Macmillan, 2006.

Recebido em: 14/08/2010

Reapresentado em: 08/04/20II

Aprovado em: 15/04/2011 